\title{
STRESS PATTERNS IN CONICAL TEETH OF REPTILES AND MAMMALS: EXPERIMENTAL AND FINITE ELEMENT ANALYSES
}

\author{
Rahul SRIVASTAVA', Adeel AHMAD² and V. Rama RAO \\ ' Geology Department, Lucknow University, Lucknow 226007, INDIA \\ ${ }^{2}$ Biophysics Laboratory, Physics Department, Nizam College Hyderabad 500 001, INDIA \\ ${ }^{3}$ Physics Department, Dharmavant College of Science and commerce Hyderabad 500 001, INDIA
}

Srivastava, R., Ahmad, A. and Rao, V. R. 1999. Stress patterns in conical teeth of reptiles and mammals: Experimental and finite element analyses. [Patrones de esfuerzo en dientes cónicos de reptiles y mamíferos: experimentación y análisis de elementos finitos.] Revista Española de Paleontología, 14(2), 269-277. ISSN 0213-6937.

\begin{abstract}
A 3- Dimensional Finite Element Analysis (FEA) of conical teeth of reptiles and some mammals, suggests that under a vertical loading condition along the longer axis of tooth, horizontal tensile stresses are produced. In dental enamel, these stresses are distributed mainly in two horizontal directions, i.e. in X direction and in $\mathrm{Z}$ direction. The empirical observation of stresses possibly leading to the vertical failure of the teeth was obtained through Universal Testing Machine (UTM) using recent unicuspid teeth of crocodiles, varanus and canines of pig, cat and dog. The horizontal development of Hunter Schreger Bands (HSBs) has been observed in the enamel of canines of herbivore and carnivore mammals, which seems to be an effective structural strategy to counter splitting of tooth enamel under vertical loading. In contrast, the unicuspid teeth of reptiles lack the HSBs, and are more susceptible to failure. However, as reptilian teeth are continuously replaced, the damage is negligible.
\end{abstract}

Keywords: Conical teeth, reptiles, mammals, SEM, FEA, UTM, tensile stresses, reinforcement.

\section{RESUMEN}

El análisis de elementos finitos (AEF), en tres dimensiones, de los dientes cónicos de algunos reptiles y mamíferos sugiere que se produce un esfuerzo tensional horizontal cuando el diente es sometido a carga vertical sobre el eje dental más largo. Este esfuerzo tensional se distribuye en el esmalte dental principalmente en dos direcciones horizontales, i.e. en las direcciones X y Z. Los datos empíricos de esfuerzos que posiblemente llevaron a la rotura vertical del diente fueron obtenidos mediante una máquina de contrastación universal (MCU) utilizando dientes unicuspidados recientes de cocodrilos, varanos, y caninos de cerdos, gatos y perros. El desarrollo horizontal de bandas de Hunter Schreger (BHS) ha sido observado en el esmalte de los caninos de mamíferos herbívoros y carnívoros, lo que parece ser una estrategia estructural efectiva contra la rotura del esmalte dental por carga vertical. En cambio, los dientes unicuspidados de reptiles carecen de bandas de este tipo y son más susceptibles de rotura. Sin embargo, como los dientes de los reptiles son continuamente remplazados, el daño es insignificante.

Palabras clave: Dientes cónicos, reptiles, mamíferos, MEB (microscopía electrónica de barrido), AEF (análisis de elementos finitos), MCU (máquina de contrastación universal), esfuerzos tensionales, reforzamiento dental.

\section{INTRODUCTION}

Dental enamel is a hard dense material made up of apatite crystallites (crystallites of hydroxy apatite), whose principal function is to gnaw chew, grind and tear the food without breaking or cracking. The present paper examines both theoretically and experimentally, the tearing stresses in conical shaped teeth of some reptiles and mammals and their relationships with the internal structure of enamel as observed under the Scanning Electron Microscope (SEM). In light of this, the objective of the present work includes biomechanics of conical teeth of selected reptiles and mammals, backed by 3-D Finite Element (FE) modelling and experimental load 


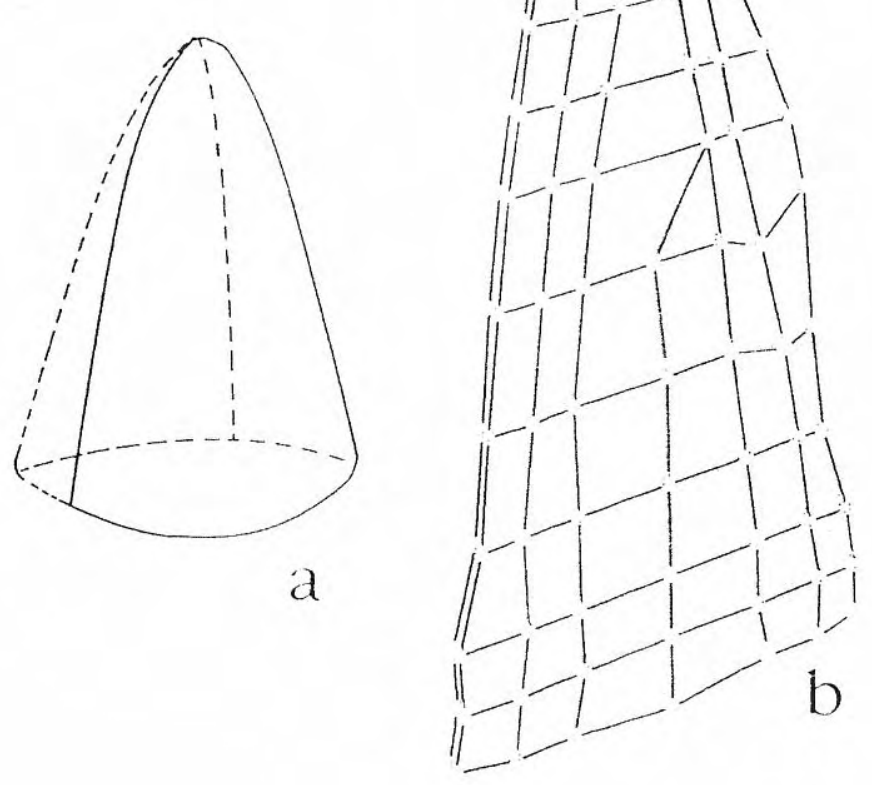

Figure 1. a. Triangular segment model. The surface of one quarter of conical tooth (illustrated with solid line) has been modelled in the study. b. Triangular segment of conical tooth divided into 53 hexa elements and 3 penta elements to form an FE model. The effect of unmodelled parts of the conical tooth are simulated by eliminating rotations and translations of the bottom and two adjacent boundaries of the model (marked by solid lines; after Rensberger, 1992). The arrow marks the direction of load for FEA.

analysis in laboratory using Universal Testing Machine (UTM). This would help delineate the direction of principal stresses in unicuspid teeth of reptiles and canines of mammals for better understanding of their functional significance in the light of enamel microstructure as observed under SEM.

Previous studies so far made contained no experimental evidences, in which the actual tooth is subjected to load to analyse the direction of failure, though some shell models made up of glass-epoxy have been analysed in laboratory for load analyses (Koenigswald et al., 1987; Rensberger, 1992).

Earlier to this 3-D FE analyses have been done to calculate the stresses in fossil and recent perissodactyl mammals using hexa elements (Rensberger, 1993, 1995a,

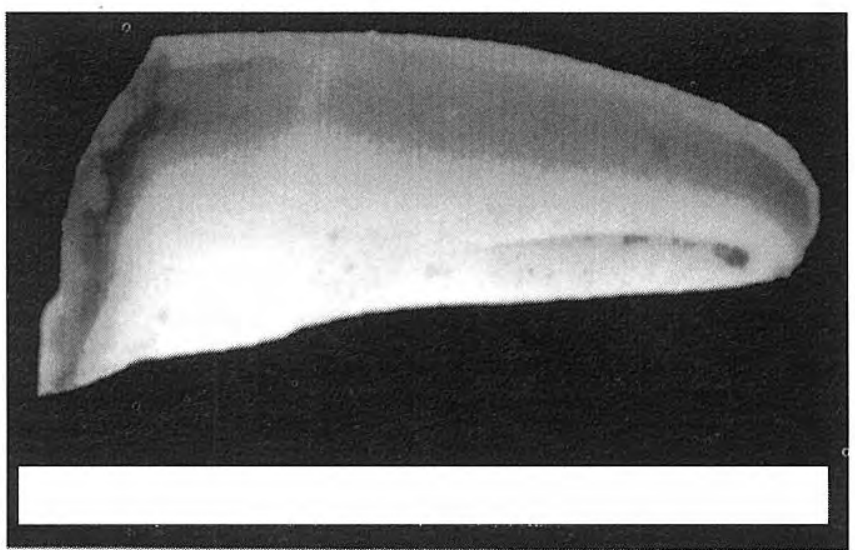

Figure 2. A recent canine of cat showing vertical premortem notch resulting from mastication of food. The structure has been helpful in deciphering the direction of load for FE analysis. Scale bar $=1 \mathrm{~cm}$.

1995b) but no such analysis has been done so far for unicuspid conical teeth. Prior to this many models for conical teeth, herbivore molars were produced in 2-D plane using quadrilateral plate elements and shell elements (Koenigswald et al., 1987; Pfretzschner, 1988b, 1992; Rensberger, 1992; Marx, 1995). The 2-D plate elements do not provide stresses in the direction which is not parallel to the elements, i.e. in the direction of thickness of the enamel. In the present study the 3-D hexa elements have been used to calculate the stresses in canines of some herbivore and carnivore mammals and

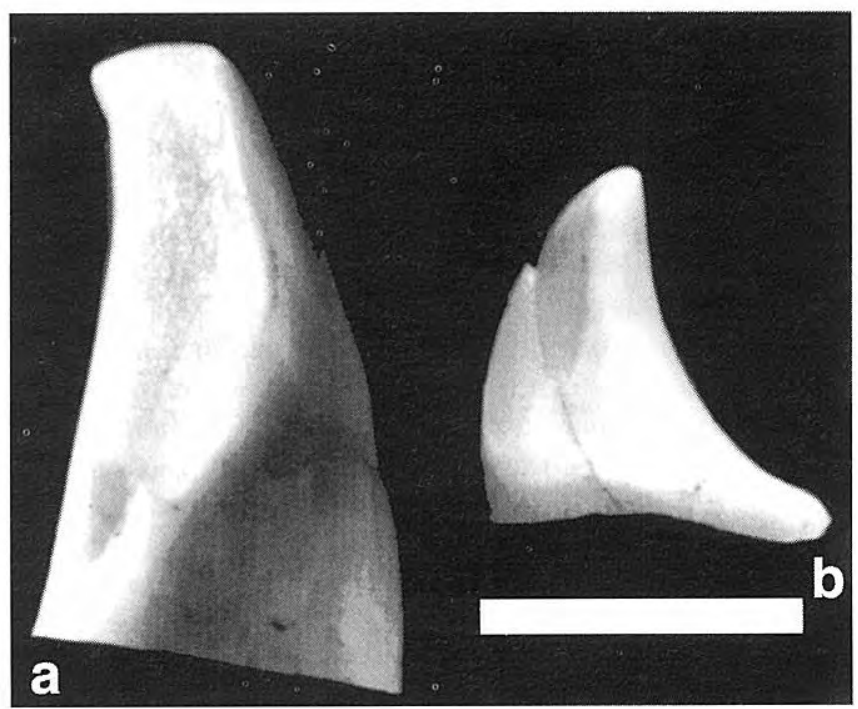

Figure 3. a. A recent canine of pig showing vertical pit which has been smoothened by tearing abrasion. b. A recent canine of pig showing vertical pit which has been smoothened by tearing abrasion. A postmortem vertical crack formed as a result of pressing the tooth (between the thumb and the first finger) is also seen in the area of vertical pit. The structure provides an information to decipher the direction of chewing load on mammalian canines. Scale bar $=1 \mathrm{~cm}$. 


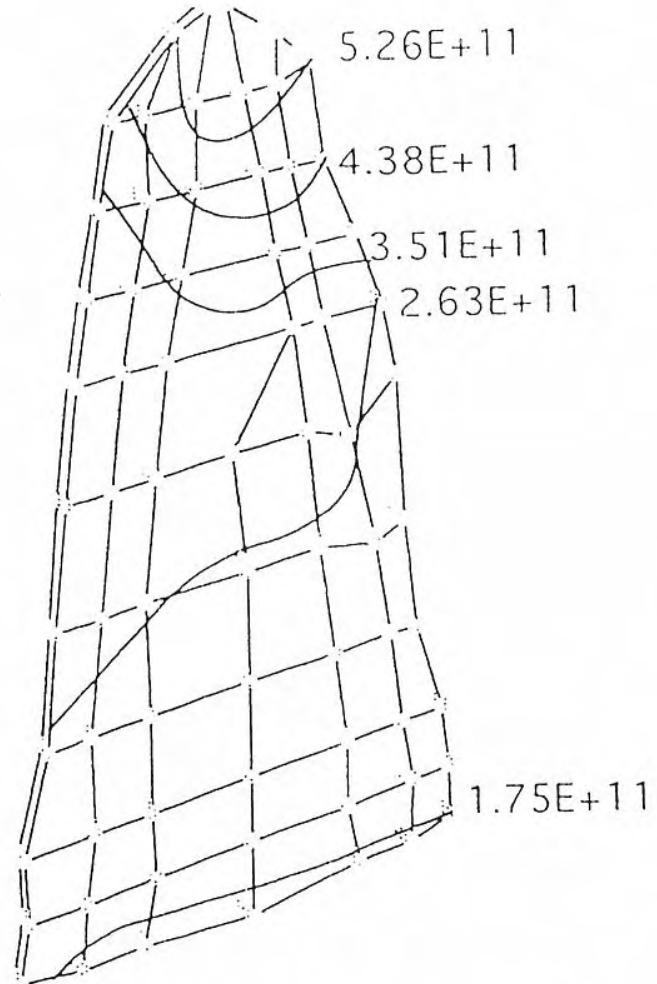

Figure 4. FEA model of conical tooth showing areas of stress intensities and their magnitude. The stress magnitude decreases as we move away from the area of load application.

unicuspid teeth of reptiles. The 3-D analysis provides stresses in all the three orthogonal directions of the enamel, i.e. along the length, width and thickness.

The FEA allows the calculation of stresses in objects of any shape and complexity. In FEA, the models are formulated as a series of connected subunits called elements of simple shape and size.

In unicuspid teeth of reptiles and canines of mammals, enamel encloses dentine from all the directions and it may be considered to be made up of upright triangular plates. The computer modelling of tearing events in unicuspid conical teeth have shown that the triangular enamel plates are loaded equally on any moment during the function of catching prey and tearing the food. The finite element model of unicuspid teeth of reptiles and canines of mammals can therefore be simplified by modelling only a 3-D triangular segment of tooth of enamel (sensu Rensberger, 1992). The result of loading of such a segment would represent the kind and direction of stresses in complete tooth (Koenigswald et al., 1987; Pfretzschner, 1988a, 1988b; Rensberger, 1992; Marx 1995).

\section{MATERIAL AND METHODS}

To observe load response in relation to the shape, conical teeth of a variety of reptiles and mammals were taken, although the internal structure of these are known to differ, they all are marked by a similar conical shape.

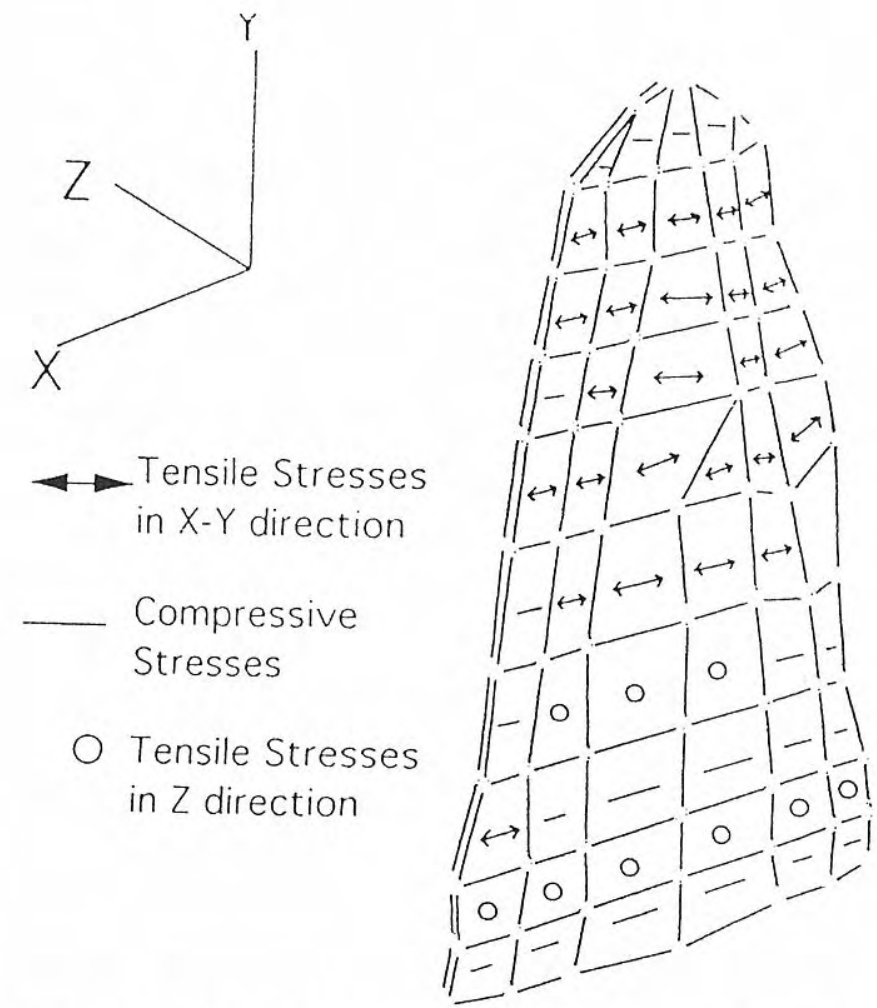

Figure 5. FEA model of conical tooth showing direction and kind of stresses produced in the enamel due to vertical loading.

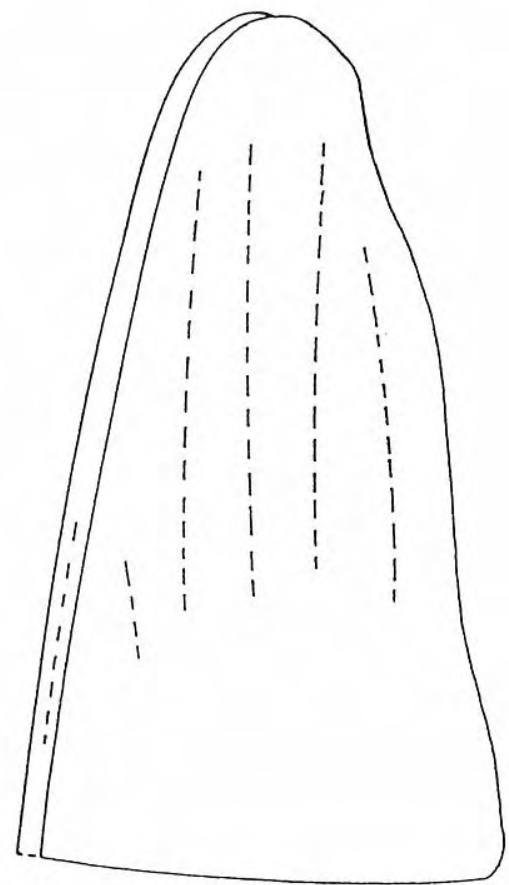

Figure 6. Probable direction of failure of tooth under vertical loading condition as inferred from the directions of maximum tensile stresses in conical tooth.

For SEM analysis, the teeth of crocodile, varanus, canines of pig, cat and dog were sectioned longitudinally and transversely. The sectioned teeth were ground and polished. The etching techniques was adjusted to the 


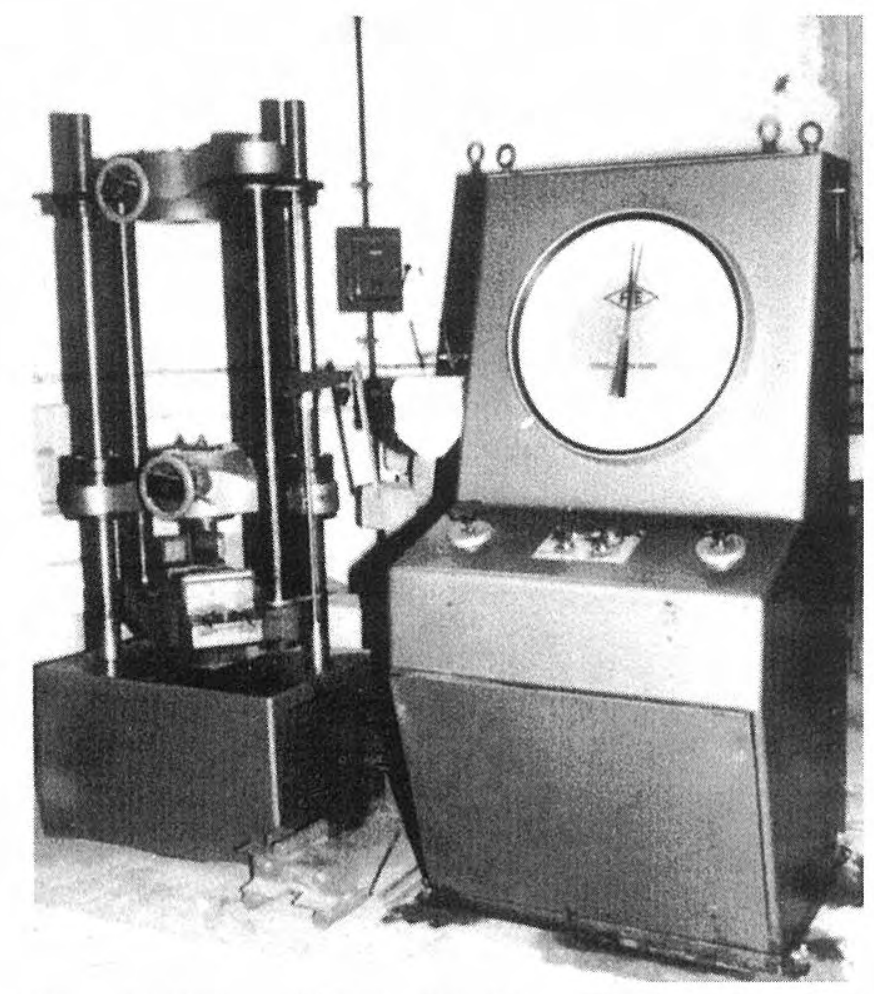

Figure 7. Universal Testing Machine (UTM) used for load analysis in laboratory.

level of structural complexity being investigated, i.e. the orientation of the HSBs (if present; they are absent in the case of reptiles) in relation to the tearing stresses (sensu Koenigswald and Clemens, 1992). Therefore, a very light etching of the tooth surface was done with $5 \% \mathrm{HCl}$. At some places, (in mammalian canines) high etching was introduced in order to observe the prism orientation in HSBs. These etched sections of the teeth were then coated with gold to make the surface conducting and were viewed under the SEM (JEOL JSM T-330, installed in the Department of Geology, Lucknow University) at various magnification ranging from 35- 3500 (accelerating voltage $15 \mathrm{kv}$ ).

For the Finite Element Analysis (FEA), the triangular segment of enamel plates of conical teeth was modelled as a series of hexa elements (Figs. 1a and 1b). The modelling was done with the help of a FEA software LapFEA (2000 nodes version, native for Power Macintosh) on a Power Macintosh (6100/66) computer available with first author of this paper.

While modelling the teeth, the material was considered to be isotropic, i.e. it has the same elastic modulus in every direction. In this assumption, error would be uniform and hence would not affect the results. Enamel prisms may be orthotropic, i.e. they may have different moduli of elasticity along the long axis of prisms in comparison to a direction perpendicular to them. Since, a small chunk of enamel consists of a number of prisms in diverse direction, hence it is not possible to calculate the Young's Modulus values for the dental enamel of different mammals excepting some insectivores (Rensberger, 1992). In the present work, for
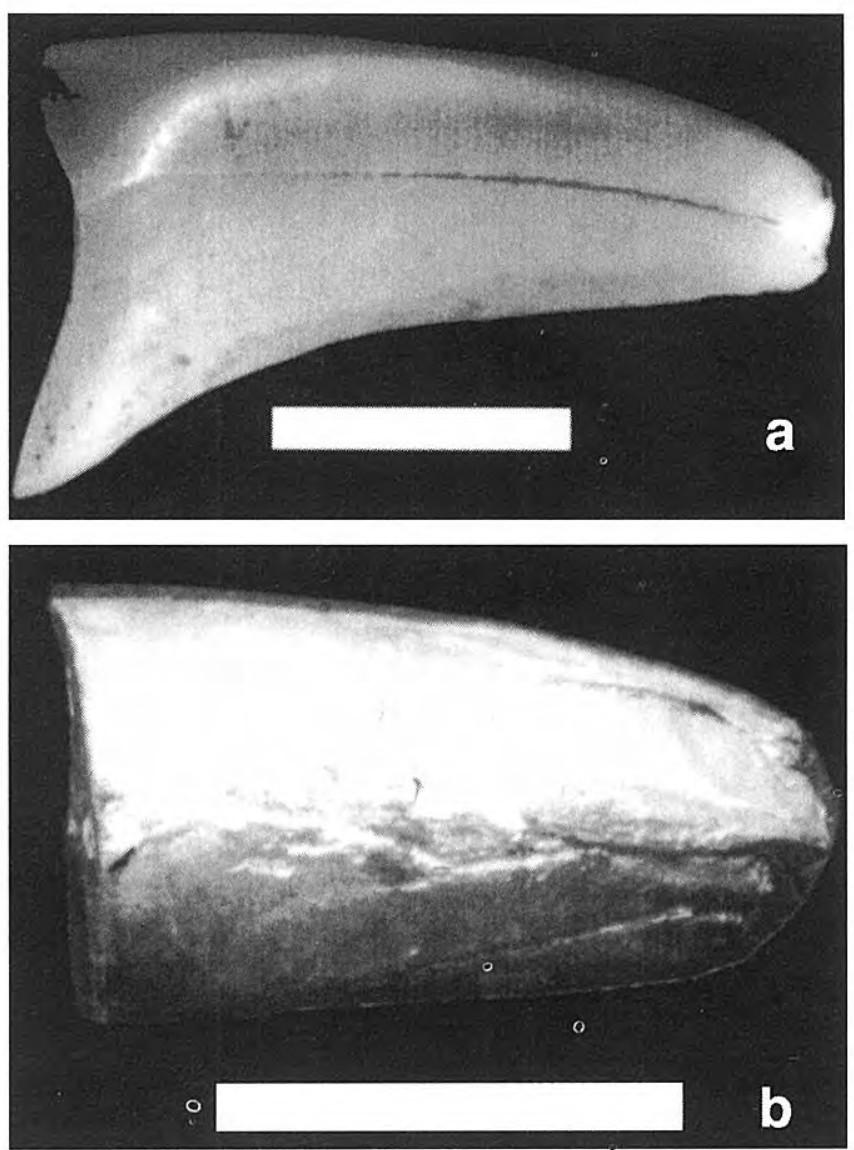

Figure 8. a. A recent canine of dog showing vertical crack produced in laboratory by loading the tooth with the help of UTM. The cracks have started appearing from apex to base under the increasing load conditions. b. A recent conical tooth of crocodile showing development of vertical cracks. A chipping of enamel is seen in the centre of tooth due to failure of enamel along the longer axis in $\mathrm{Z}$ direction (the tensile stresses are produced in a horizontal plane in $\mathrm{Z}$ direction the direction of enamel thickness). Scale bar $=1 \mathrm{~cm}$.

the FEA, the Young's modulus, Poisson's Ratio, Shear Modulus and Mass Density values for the enamel as a general were taken (Rensberger, pers. comm.; Waters, 1980).

Young's Modulus (Stress/Strain) $=0.040 \mathrm{MN} \mathrm{mm}^{-2}$

Poisson's Ratio $=0.3$

Shear Modulus $($ Shear stress/strain $)=0.0154$ E6 N $\mathrm{mm}^{-2}$

Mass Density $=3.0310^{-3} \mathrm{~N}-\mathrm{sec}^{2} / \mathrm{mm}^{4}$

With these values the absolute stress magnitude from the teeth models could not be obtained but relative magnitudes and stress directions within a model could be calculated which do not affect the objectives of the work. Though it is not possible to simulate the natural condition of mastication (because in nature, the dentition works in union), while modelling the tooth the natural condition was kept in mind and hence a static vertical load (snow load, Koenigswald et al., 1987) was applied on the tip of the tooth. The base of the tooth was kept fixed 


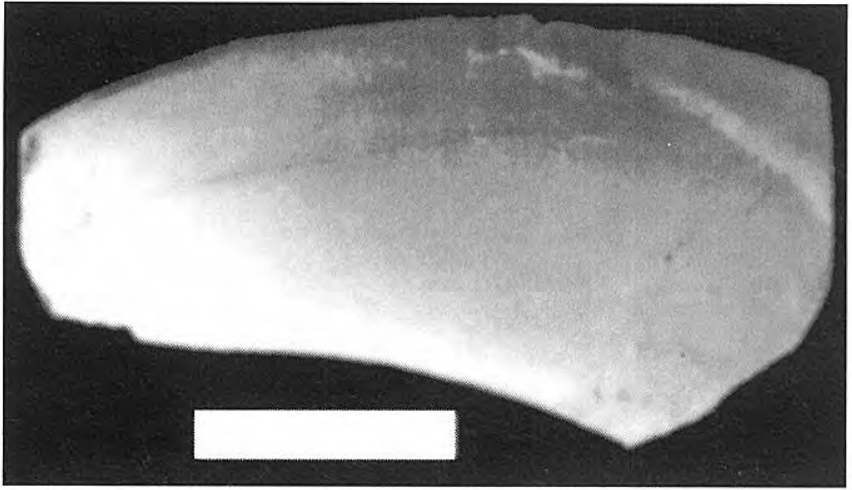

Figure 9. A recent canine of pig showing vertical cracks produced in laboratory by loading the tooth with help of UTM. The cracks have started appearing from apex to base under the increasing load conditions. Scale bar $=1 \mathrm{~cm}$.

considering that the it is anchored in the jaw (Fig.1b). The load direction was inferred from occlusal features such as striae, notches, vertical pits and surface relief present on teeth (Figs. 2, 3a and 3b), which are formed as a result of various masticatory processes (Greaves, 1973; Rensberger, 1973, 1992; Koenigswald et al., 1987). The resultant tensile stresses were calculated at the centre of the elements using a solver MSC/pal2. The principal stresses were extracted from the result, because brittle materials are weaker under tensile than compressive stress and usually fail due to tension (even when the external force is mainly of a compressive nature; Rensberger, 1992). The stresses intensities in the model were calculated and plotted (Fig. 4). The direction of maximum tensile stresses were plotted on the model of conical tooth (Fig. 5) and the probable directions of propagation of cracks (perpendicular to the direction of maximum tensile stress at a given point) were determined (Fig. 6). In the present study the absolute magnitude of stresses in enamel would be unrealistic, but the study is

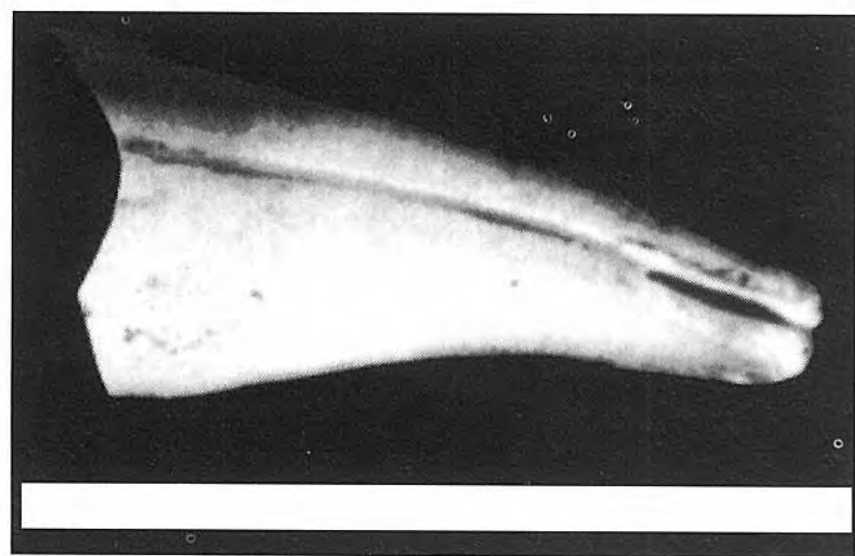

Figure 10. A recent canine of cat showing vertical fracture formed as a result of pressing the boiled tooth between the thumb and the first finger (the teeth were boiled in order to reduce their stiffness so they could be pressed with the hands). Scale bar $=1 \mathrm{~cm}$.

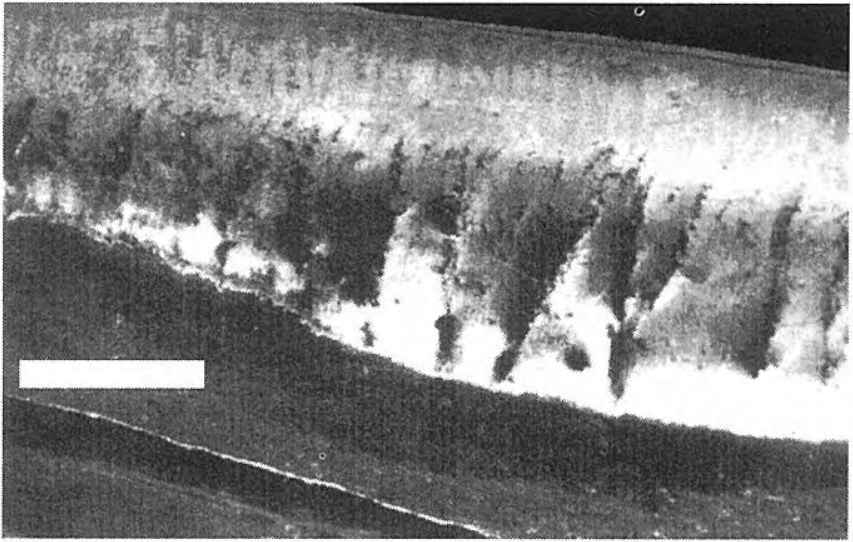

Figure 11. Longitudinal section of a recent canine of cat showing development of horizontal Hunter Schreger Bands (HSBs). Apex of the tooth is towards the left side of the Photograph. Scale bar $=500 \mu \mathrm{m}$.

mainly concerned with the directions of stresses and these approximates the directions in real teeth. To test this assumption, the conical teeth of crocodile, varanus, cat, dog and pig were loaded in laboratory with the help of Universal Testing Machine (UTM) of 10 ton capacity and $100 \mathrm{~kg}$ capacity, loading at the rate of $1 \mathrm{kgf}$ (Fig. 7). The machine is available with the last two authors of the paper, and is used mainly to calculate strength of materials under compression only. The limitations of the machine do not allow users to calculate stresses on an object due to pulling load (= wind load, Koenigswald et al., 1987). For compressive load analysis the samples were held between two circular jaws in upright condition with the help of metallic chunk and the load of $1 \mathrm{kgf}$ was

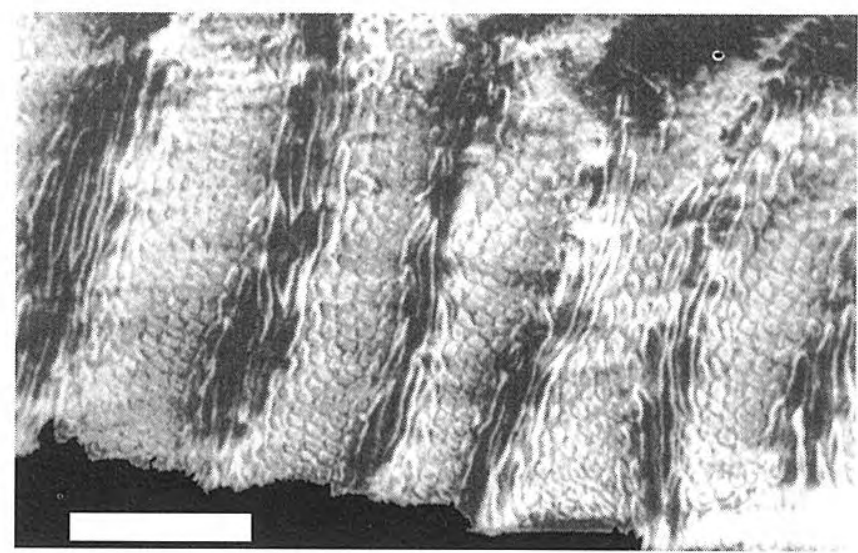

Figure 12. Longitudinal section of a recent canine of cat showing decussating HSBs. The neighbouring HSBs are at right angles to each other (in X-Y direction and in $Z$ direction) to hinder the vertical cracks in $\mathrm{X}-\mathrm{Y}$ direction and in $\mathrm{Z}$ direction. The HSBs going in the $\mathrm{Z}$ direction are transversely sectioned and those in $\mathrm{X}-\mathrm{Y}$ direction are longitudinally sectioned. Apex of the tooth is towards the left side of the Photograph. Scale bar $=500 \mu \mathrm{m}$. 


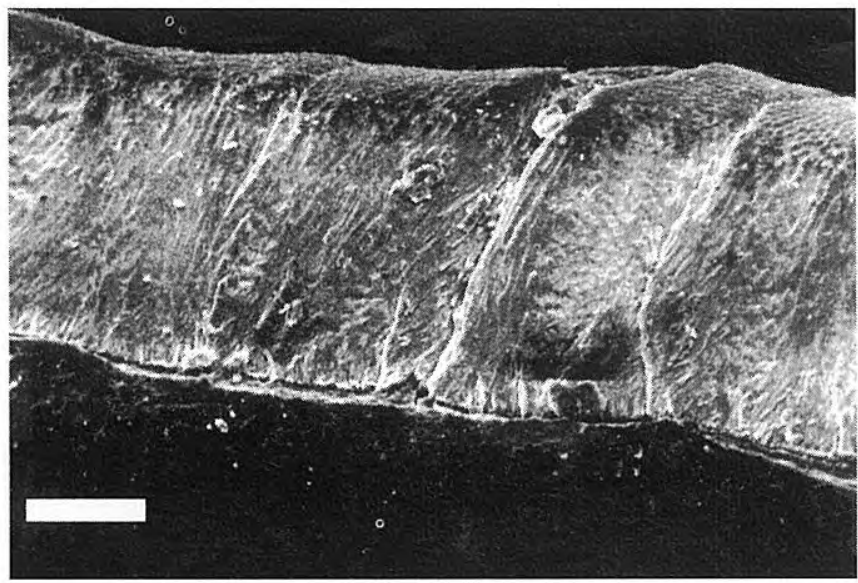

Figure 13. Longitudinal section of a recent canine of pig showing development of horizontal HSBs. Apex of the tooth is towards the right side of the Photograph. Scale bar $=50 \mu \mathrm{m}$.

applied in the intervals of time of 1 minute and result were noted (Figs. 8a, 8b and 9). In another case one tooth was subjected to compressive load along the shorter axis of tooth also, i.e. in transverse direction.

For more results, 20 canines of recent cat, dog and pig were boiled in water for about 2-3 hours. The teeth were boiled in water in order to reduce their stiffness so that they could be easily compressed along the longer axis with the hands.

The theoretical results of FEA and laboratory results of UTM were compared with empirical evidence of stresses in actual teeth. Teeth of recent crocodile, varanus, dog, pig and cat were examined for premortem notches, pits and cracks under the assumption that they were caused by tearing load. The cracks, notches and pits with rounded edges and vertical hairline cracks were identified as premortem (Rensberger, 1987). Additionally, the data was compared with postmortem cracks also formed due to pressing of boiled teeth along their longer axis between the thumb and the first finger (Fig. 10) .

Finally, the crack directions in conical teeth were compared with the absence/presence and orientation of HSBs in the unicuspid teeth of reptiles and canines of mammals.

\section{OBSERVATIONS}

The SEM studies suggest that the enamel microstructure in canines of recent cat, dog and pig contains horizontal HSBs in which the prisms bands are oriented in horizontal planes. The neighbouring bands are at right angle (Figs. 11-16) as observed earlier in canines of extant Panthera leo, Martes foina and Equus przewalkskii (Koenigswald and Pfretzschner, 1987; Pfretzschner, 1988b, 1992). The radial enamel was found to be absent in all the canines of studied mammals. The enamel microstructure of varanus and crocodile teeth enamel contains prismless structure (Figs. 17 and 18) as

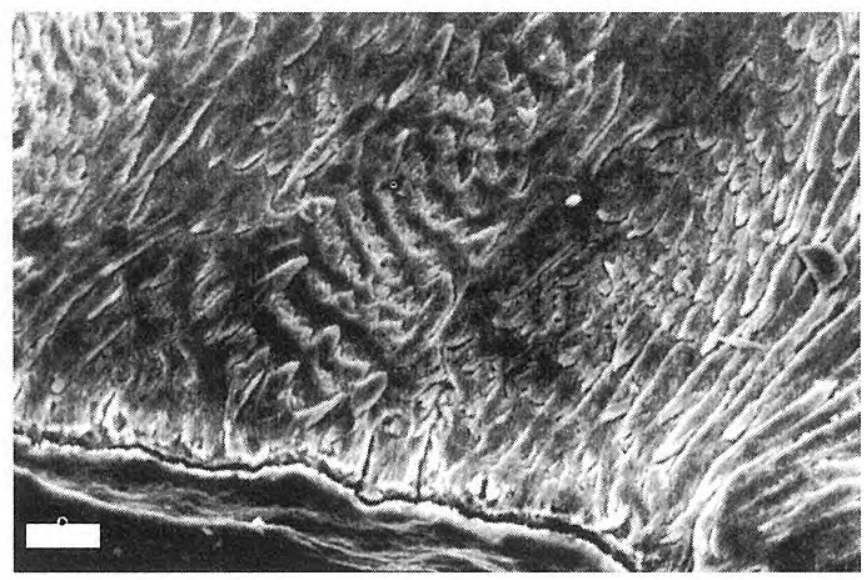

Figure 14. Longitudinal section of a recent canine of pig showing orientation of neighbouring HSBs. Apex of the tooth is towards the right side of the Photograph. Scale bar $=10 \mu \mathrm{m}$.

observed earlier by various workers (Carlson, 1990; Koenigswald and Clemens, 1992; Sander, 1997; Koenigswald and Sander, 1997).

The FEA studies suggest that when vertical load is applied to the conical teeth, the stresses of relatively higher intensities are produced in the area which is close to the point of load application; the relative intensities of stresses decrease as we move away from the point of load application, i.e. towards the base of the tooth (Fig. 4). In teeth, both compressive and tensile stresses were noticed. The compressive stresses were observed mainly in the area of apex and base of the tooth. The major part of tooth was found to be under tension. The tensile stresses were observed mainly in two horizontal direction. The tensile stresses in $\mathrm{X}-\mathrm{Y}$ direction were noticed in the upper region and the middle region of the tooth, where as the lower region of the tooth remains under tension having orientation of tensile stresses in $\mathrm{Z}$ direction, i.e. in the direction of enamel thickness (Fig. 5).

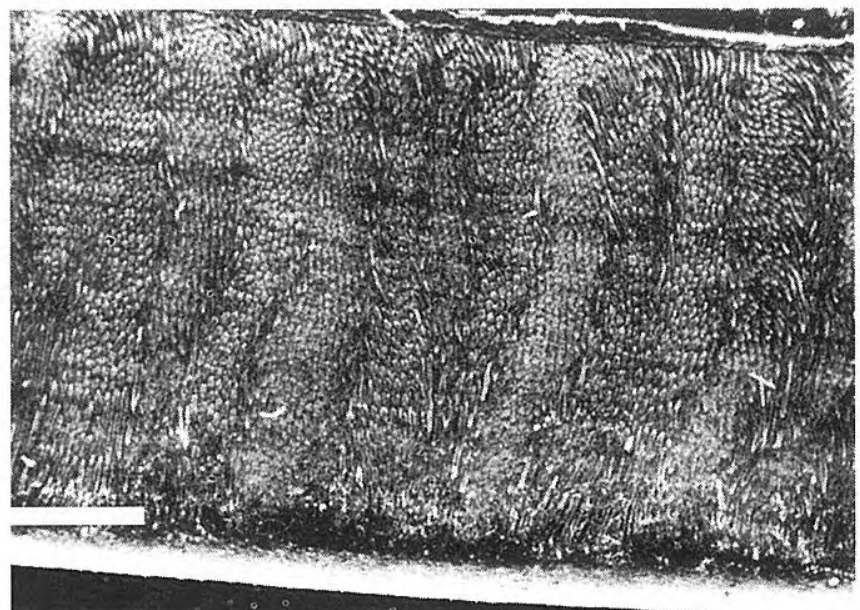

Figure 15. Longitudinal section of a recent canine of dog showing horizontal HSBs in X-Y direction and $\mathrm{Z}$ direction. Apex of the tooth is towards the left side of the Photograph. Scale bar $=100 \mu \mathrm{m}$. 


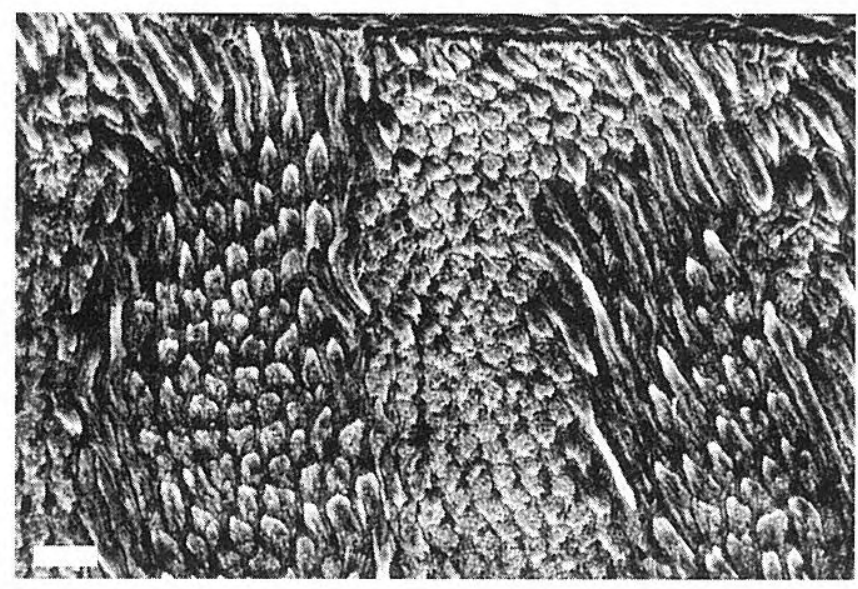

Figure 16. Longitudinal section of a recent canine of dog showing orientation of neighbouring HSBs near Enamel-Dentine Junction (EDJ). The orientation of HSBs hinders the cracks in X-Y direction and $\mathrm{Z}$ direction (the direction of enamel thickness). Apex of the tooth is towards the left side of the Photograph. Scale bar $=10 \mu \mathrm{m}$.

From the direction of tensile stresses, most probable direction of failure was inferred which was found to be vertical along the longer axis of teeth (Fig. 6).

The UTM (Fig. 7) analysis suggests that when teeth of cat, dog, pig, varanus and crocodiles were placed under an increasing vertical load condition the failure of the tooth takes place. The cracks starts appearing from apex to base (Figs. 8 and 9) in all the teeth (in static load condition cracks start appearing from base to apex, Rensberger, 1987). First of all the tip portion is crushed to form a base, and then the tooth starts breaking along the vertical axis. First the apex, then the middle portion and at the end, the portion near the base breaks vertically into pieces. When a tooth is loaded along the transverse axis (compressive load) the entire tooth is found to be broken just in a single loading suggests that compressive strength of the brittle material 'enamel' is far lesser in transverse direction than in longitudinal direction.

The boiled teeth were also compressed between the first finger and thumb and the direction of failure was observed along the longer axis of teeth (Fig. 10) as observed in the case of UTM.

\section{RESULTS AND DISCUSSION}

The direction of failure observed by FEA, UTM and manual compression were compared. The results indicate that the inferred cracks' directions in the FE models were similar to the cracks produced in the teeth in laboratory experiments.

The results of FE analysis of conical teeth suggests that at vertical loading condition the maximum tensile stresses are oriented in two directions in horizontal planes (Fig. 5) one in the direction of width of tooth (X direction) and other in the direction of thickness of enamel ( $Z$ direction). These stresses may be responsible

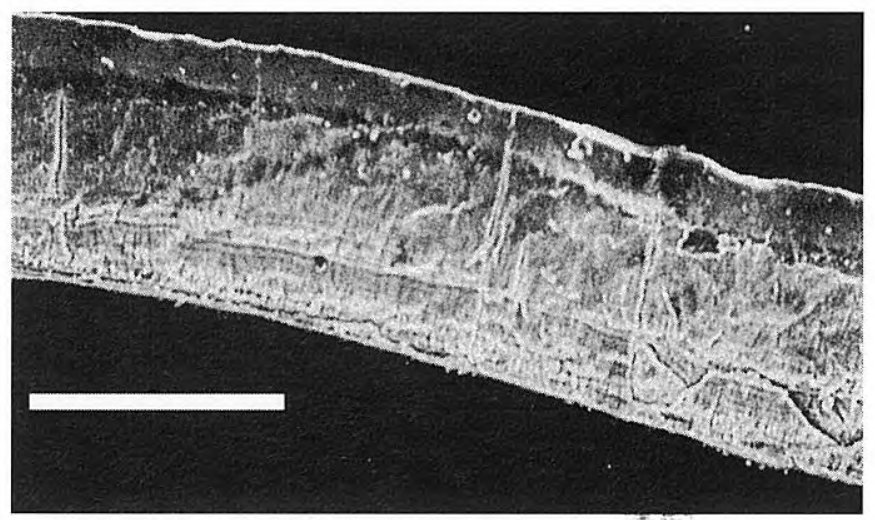

Figure 17. Longitudinal section of a recent tooth of crocodile showing prismless enamel band. Enamel-Dentine Junction (EDJ) towards the bottom of the photograph. Scale bar $=100 \mu \mathrm{m}$.

for the development of vertical cracks in enamel.

The "Universal Testing Machine" (UTM) was found to be very useful in simulating the natural condition of teeth in jaw and applying pressure from different angle. The results of UTM corresponds to the FEA results. By applying load of $1 \mathrm{kgf}$ at the interval of 1 minutes the vertical cracks were noticed in the teeth of crocodile, varanus, canines of pig, cat and dog.

The FEA results, UTM results were found to be consistent with the premortem notches, pits and cracks, which tend to have vertical orientation (Figs. 2 and 3).

The shape of teeth is an important factor to determine the direction of stresses at various kind of loading conditions mentioned earlier. The mammalian molars have different and rather complicated dental morphology when compared to incisors and canines. The direction of chewing forces are also different in molars of different animals. To understand the functional significance of the geometry of enamel microstructure in molars of various fossil and recent herbivore mammals the 3-D FE analyses were done on the teeth of fossil and recent herbivore perissodactyl mammals. In these mammals HSBs were noticed to be adaptive to accommodate the maximum tensile stresses produced due to chewing action (Rensberger, 1993, 1995a, 1995b). The HSB prisms exhibit concordant changes in orientation. The direction of change in orientation of the prisms in one band is opposite to that in adjacent bands, thus producing "decussation of prism" (Koenigswald and Clemens, 1992). Among herbivorous mammals, Japanese monkeys (Macaca fuscata) use sloping mandibular third premolars and maxillary canines for eating stalks of plants, seeds and sweet potatoes with grasshoppers, cicadas etc., and their third premolars are heavily worn (Hojo, 1996). But their mandibular third premolars do not show cracks, because they have horizontal Hunter-Schreger bands for hindering cracks (Hojo, 1996).

The shape of unicuspid teeth in reptiles and canines of almost all herbivore and carnivore mammals, is conical with a slight variation. The use and function of canines in all the mammals is nearly similar and hence the direction of masticatory forces (tearing forces) are identical, i.e. the 


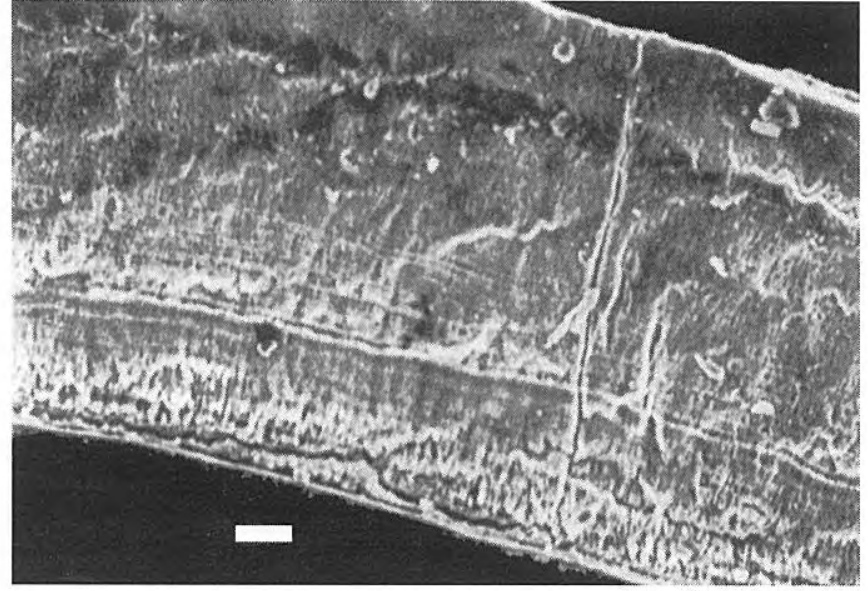

Figure 18. Enamel surface shown in Fig. 17, at higher magnification. The apatite crystallites do not show any kinds of prisms development and therefore, the vertical cracks are unaffected by the prismless enamel structure as seen in the Photograph. Enamel-Dentine Junction (EDJ) towards the bottom of the photograph. Scale bar $=10 \mu \mathrm{m}$.

direction parallel to the longer axis of canines. In unicuspid teeth of reptiles, during predation, the load is applied on the apex of teeth vertically downward along the longer axis. This direction is similar to the direction of masticatory forces in canines of most mammals.

During tearing and breaking processes a high degree of vertical pressure is exerted on the canines of herbivore and carnivore mammals resulting into horizontal tensile stresses (the loading conditions in the canines of astrapotheres were found to be different leading to different kind of stress pattern; Rensberger and Pfretzschner, 1992). If these stresses exceeds the tensile strength of enamel the vertical cracks takes place. To hinder these cracks the horizontal development of HSBs have been noticed in the canines of herbivore and carnivore mammals since the time of their evolution. However, the microstructure of the canine enamel in the astrapotheres is distinct. The lower canine enamel of the Parastrapotherium (of Oligocene age) shows a form of vertical decussation modified by a wave like bending of prism zones, whereas the decussation in the rhinocerotoid canine is horizontal (Rensberger and Pfretzschner, 1992).

The canines of herbivore and carnivore mammals are probably not used for the purposes in which wear takes place, this might have been the reason for the absence of radial enamel in their canines, which provides best reinforcement against wear (Rensberger and Koenigswald, 1980; Fortelius, 1984, 1985).

In unicuspid teeth of reptiles the vertical cracks can not be hinder as they lack horizontal HSBs in their enamel and possess prismless enamel (Carlson, 1990; Sander, 1997; Koenigswald and Sander, 1997). They show a tendency of continuous shedding and limited function of teeth.

\section{CONCLUSION}

Conical shaped teeth including unicuspid teeth of reptiles and canines of herbivore and carnivore mammals demonstrate the horizontal tensile stresses in their enamel during tearing and breaking processes. These stresses are oriented mainly in two directions, i.e. in $\mathrm{X}$ direction (the direction of tooth width) and in $\mathrm{Z}$ direction (the direction of enamel thickness) and may be responsible for the development of vertical cracks in the unicuspid teeth of reptiles and canines of mammals.

The development of horizontal Hunter Schreger Bands (HSBs) in $\mathrm{X}$ and $\mathrm{Z}$ direction in canines of mammals was found to be an adaptive feature against the vertical failure. The absence of radial enamel in the canines may be related to the negligible wear of the teeth.

The unicuspid teeth of reptiles do not show any strategy to counter these stresses; the damage is negligible in light of the continuous replacement limited functions of the teeth.

\section{ACKNOWLEDGEMENT}

Authors are grateful to Prof. Ashok Sahni and Prof. Dr. H. H. Schleich for reading the manuscript and two reviewers for reading the text carefully and offering fruitful suggestions and corrections. First author is indebted to Prof. Dr. J. M. Rensberger, who took pain in teaching him the basics and the methods of FEA modelling. Dr. Rajeev Patnaik is thankfully acknowledged for providing dental elements of Siwalik crocodiles. The financial assistance for this work was provided by DST in the form of Young Scientists project (SR/SY/A-09/94) to first author, is also gratefully acknowledged. Various laboratories facilities were provided by the Head, Geology Department, Lucknow University, Lucknow (India) and the Director, Fuhlrott Museum, Wuppertal (Germany).

\section{REFERENCES}

Carlson, S. J. 1990. Vertebrate dental structures. In: Skeletal biomineralization: patterns, processes and evolutionary trends (Ed. J. G. Carter). Van Nostrand Reinhold, NY, 1, 531-536.

Fortelius, M. 1984. Vertical decussation of enamel prisms in lophodont ungulates. In: Tooth Enamel, IV (Eds. R.W. Fearnhead and S. Suga). Elsevier, Amsterdam, 427-431.

Fortelius, M. 1985. Ungulate cheek teeth: developmental, functional and evolutionary interrelations. Acta Zoologica Fennica, 180, 1-76.

Greaves, W. S. 1973. The inference of jaw motion from tooth wear facets. Journal of Paleontology, 47, 10001001 .

Hojo, T. 1996. Quantitative analyses of microwear and honing on the sloping crest of the P3 in female Japanese monkeys (Macaca fuscata). Scanning Microscopy, 10, 727-736.

Koenigswald, W. v. and Clemens, W. A. 1992. Levels of complexity in the microstructure of mammalian enamel 
and their application in studies of systematics. Scanning Microscopy, 6, 195-218.

Koenigswald, W. v. und Pfretzschner, H. U. 1987. HunterSchreger-Bander im zahnschmelz von saugetieren (Mammalia). Zoomorphology, 106, 329-338.

Koenigswald, W. v. and Sander, P.M. 1997. Glossary of terms used for enamel microstructures. In: Tooth Enamel Microstructure (Eds. W. v. Koenigswald and P.M. Sander), Balkelma, Rotterdam, 267-280.

Koenigswald, W. v., Rensberger, J. M. and Pfretzschner, H. U. 1987. Changes in the tooth enamel of early Paleocene mammals allowing increased diet diversity. Nature, 328, 150-152.

Marx, A. 1995. Analysis of masticatory stresses in hypsodont molars of herbivores by finite element modelling. In: Aspects of Dental Biology: Palaeontology, Anthorpology and Evolution (Ed. J. Moggi-Cecchi), 129146.

Pfretzschner, H. U. 1988a. Structural reinforcement and crack propagation in enamel. Mémoires du Muséum National d'Histoire Naturelle, Paris, ser. C. (Eds. D. E. Russell, J. -P. Santoro and D. Sigogneau-Russell), 53, 133-143.

Pfretzschner, H. U. (1988b). Biomechanik der schmelzmikrostruktur in den backenzahnen von grossaugern. Palaeontographica, 1-169.

Pfretzschner, H.U. 1992. Enamel microstructure and hypsodonty in large mammals. In: Structure, Function and Evolution of Teeth (Eds. P. Smith and E. Tchernov), 147-162.

Pfretzschner, H. U. 1995. Analysis of masticatory stresses in hpsodont molars of herbivores by finite element modelling. In: Aspects of Dental Biology: Palaeontology, Anthorpology and Evolution (Ed. J. Moggi-Cecchi), 110128.

Rensberger, J. M. 1973. An occlusion model for mastication and dental wear in herbivorous mammals. Journal of Paleontology, 47, 515-528.
Rensberger, J. M. 1987. Cracks in fossil enamels resulting from premortem vs. postmortem events. Scanning Microscopy, 1, 631-645.

Rensberger, J. M. 1992. Relationship of chewing stress and enamel microstructure in rhinocerotoid cheek teeth. In: Structure, Function and Evolution of Teeth (Eds. P. Smith and E. Tchernov), 163-183.

Rensberger, J. M. 1993. Adaptation of enamel microstructure to differences in stress intensity in the Eocene perissodactyl Hyracotherium. In: Structure, Formation and Evolution of Fossil Hard Tissues (Eds. I. Kobayashi, H. Mutvei and A. Sahni), 131-145.

Rensberger, J. M. 1995a. Determination of stresses in mammalian dental enamel and their relevance to the interpretation of feeding behaviours in extinct taxa. In: Functional Morphology and Vertebrate Paleontology (Ed. J. Thomason), 151-172.

Rensberger, J. M. 1995b. Relationship of chewing stresses to 3-D geometry of enamel microstructure in rhinocerotoids. In: Aspects of Dental Biology: Palaeontology, Anthorpology and Evolution (Ed. J. Moggi-Cecchi), 129-146.

Rensberger, J. M. and Koenigswald, V. v. 1980. Functional and phylogenetic interpretation of enamel microstructure in Rhinoceroses. Palaeobiology, 6, 477-495.

Rensberger, J. M. and Pfretzschner, H. U. 1992. Enamel structure in astrapotheres and its functional implications. Scanning Microscopy, 6, 495-510.

Sander, P.M. 1997. Non-mammalian synapsid enamel and the origin of mammalian enamel prisms: The bottom-up perspective. In: Tooth Enamel Microstructure (Eds. W. v. Koenigswald and P.M. Sander). Balkema, Rotterdam, 41-62.

Waters, N.E. 1980. Some mechanical and physical properties of teeth. In: Symposia of the Society for experimental biology XXXIV, The mechanical properties of biologic materials. Cambridge University Press, 99135. 